\title{
O registro reflexivo do professor de educação infantil como arma de luta
}

\author{
The reflective registry as a teacher fighting instrument \\ El registro reflexivo del profesor como arma de lucha
}

\begin{abstract}
Cristina Carvalho ${ }^{2}$
Monique Gewerc ${ }^{3}$

Resumo: Este artigo aborda o papel do registro nos processos de formação de professores. A temática é um recorte da realização de uma pesquisa desenvolvida em 2016, um estudo de caso, sobre o Curso Normal Superior do Pró-Saber, localizado na cidade do Rio de Janeiro. O objetivo norteador da pesquisa foi conhecer uma proposta de formação de professores que se pretende alinhada com a concepção democrática de educação. A instituição de ensino superior oferece habilitação exclusivamente em Magistério da Educação Infantil e a escrita, considerada fundamental dentro da proposta pedagógica, atravessa a formação desde o primeiro dia de aula. A investigação despertou questões acerca do que registrar, que concepções de infância e educação infantil norteiam tal prática e que benefícios o hábito desse exercício pode aportar. As conclusões apontam que o registro (escrito, falado, filmado, fotografado, pintado, desenhado) é instrumento que confere poder e autonomia ao professor, uma vez que contribui para a consolidação de saberes que amalgamam a teoria com a prática do cotidiano.

Palavras-chave: Registro. Professores de educação infantil. Pró-Saber.

Abstract: This paper addresses the role of registration in teacher training processes. The theme is based on a research developed in 2016, a case study, about the Pro-Saber Normal Course, located in the city of Rio de Janeiro. The objective of the research was to know a proposal of teacher training that is aligned with the democratic conception of education. The institution of higher education offers qualification exclusively in the Teaching of Early Childhood Education and writing, considered fundamental within the pedagogical proposal, goes through the training from the first day of class. Research has raised questions about what to record, what infancy and early childhood education conception guides such practice, and what benefits the habit of such exercise can bring. The conclusions point out that the record (written, spoken, filmed, photographed, painted, drawn) is an instrument that confers power and autonomy to teachers since it contributes to the consolidation of knowledge that amalgamates theory with everyday practice.
\end{abstract}

Keywords: Records. Early childhood education teacher. Pró-Saber.

Resumen: Este artículo aborda el papel del registro en los procesos de formación de profesores. La temática es un recorte de la realización de una investigación desarrollada en 2016, un estudio de caso, sobre el Curso Normal Superior Pró-Saber, ubicado en la ciudad de Río de Janeiro. El objetivo orientador de la investigación fue conocer una propuesta de formación de profesores que se pretende alineada con la concepción democrática de educación. La institución de enseñanza superior, ofrece habilitación exclusivamente en Magisterio de Educación Infantil y la escritura, considerada fundamental dentro de la propuesta pedagógica, atraviesa la formación desde el primer día de clase. La investigación despertó cuestiones acerca de qué registrar, qué concepciones de infancia y educación infantil orientan tal práctica y qué beneficios el hábito de ese ejercicio puede aportar. Las conclusiones apuntan que el registro (escrito, hablado, filmado, fotografiado, pintado, dibujado) es instrumento que confiere poder y autonomía al professor, ya que contribuye a la consolidación de saberes que amalgaman la teoría con la práctica de lo cotidiano.

Palabras clave: Registro. Professores de educación infantil. Pró-Saber.

\footnotetext{
${ }^{1}$ Submetido em: 18 jul. 2018 - Aceito em: 02 maio 2019 - Publicado em: 18 dez. 2019

${ }^{2}$ Pontifícia Universidade Católica do Rio de Janeiro (PUC-Rio) - E-mail: cristinacarvalho@ puc-rio.br

${ }^{3}$ Pontifícia Universidade Católica do Rio de Janeiro (PUC-Rio) - E-mail: monique.g107@ yahoo.com.br
} 
$\mathrm{O}$ registro permite romper a anestesia diante de um cotidiano cego, passivo ou compulsivo, porque obriga a pensar (FREIRE, 2008, p. 58).

O tema abordado neste trabalho é parte de uma discussão mais ampla, que engloba temáticas como "professor reflexivo" e a articulação entre teoria e prática pedagógica. A premissa de que partimos é a de que o registro (escrito, falado, filmado, fotografado, pintado, desenhado) é instrumento que confere poder ao professor. A temática será fundamentada a partir de uma pesquisa realizada em 2016, em que o registro emergiu como categoria de análise de maneira contundente no trabalho de campo e despertou o desejo de aprofundamento, com intuito de compreender melhor o uso e os alcances de tal ferramenta/abordagem pedagógica.

A pesquisa se constituiu em um estudo de caso sobre o Curso Normal Superior do Pró-Saber, uma instituição de ensino superior situada na cidade do Rio de Janeiro, que oferece habilitação em Magistério da Educação Infantil. Trata-se de uma formação em que os alunos necessariamente precisam estar inseridos em uma unidade escolar de educação infantil pública ou conveniada. O princípio da formação em serviço tem por objetivo contribuir para que os alunos integrem a teoria à prática ao longo do curso, em um exercício contínuo, colaborativo e reflexivo. O registro atravessa a formação desde o primeiro dia de aula e é considerado fundamental dentro da proposta pedagógica da instituição.

Ao buscar refletir sobre temas como registro e documentação pedagógica, surgem questões acerca do que registrar, em que contexto educativo essa abordagem se insere, que concepções de infância e educação infantil norteiam a prática e que benefícios tal exercício pode aportar para o trabalho do professor da primeira infância. Em um primeiro momento, buscamos fundamentar de forma breve a escolha do tema deste artigo para, em seguida, trazermos os resultados da pesquisa. Ao final, são apresentadas algumas considerações e indagações que poderão levar a novas incursões sobre o tema.

\section{O que registrar? A escuta como exercício fundante da prática docente}

Escutar é dar valor ao outro (RINALDI, 2012, p. 209).

As Diretrizes Curriculares Nacionais para a Educação Infantil (DCNEI) (BRASIL, 2010) indicam que a aprendizagem nessa etapa educativa deve ser baseada em experiências que implicam em criação e descobertas, em um cotidiano marcado pela participação ativa das crianças. As práticas pedagógicas devem ter como eixo as interações e a brincadeira e as estratégias para a aprendizagem, que segundo o documento citado, são as diferentes linguagens, como as artes plásticas, poesia, música, teatro, tecnologias da comunicação, fotografia, entre outras.

O Documento também indica as atribuições e expectativas quanto ao trabalho do professor, é reforçada a importância de olhar a criança de modo integral e indivisivelmente em suas "dimensões expressivo-motora, afetiva, cognitiva, linguística, ética, estética e 
sociocultural" (BRASIL, 2010, p. 19). Espera-se que o professor planeje, de forma cuidadosa, estratégias que permitam a interação da criança com seus pares, com a natureza, em espaços diversos, que favoreçam o desenvolvimento de atitudes de respeito, solidariedade, reconhecimento das diferenças, cuidado com o meio ambiente, fortalecimento da autoestima, o despertar da curiosidade, do desejo de aprender. Estas estratégias se valeriam da utilização das múltiplas linguagens citadas anteriormente. Ainda são definidas como expectativas em relação às ações do professor, que observe, dialogue com as crianças, permita que as crianças se expressem oralmente, registre de maneiras múltiplas o desenvolvimento de cada uma e do grupo, respeite o ritmo de aprendizagem individual e que tudo isso seja cuidadosa e continuamente planejado (BRASIL, 2010).

As Diretrizes são claras em relação a um cotidiano que, segundo pesquisas recentes (NUNES; CORSINO; KRAMER, 2011; MICARELLO, 2013), está distante da realidade das creches e escolas brasileiras. Vale destacar que um cotidiano voltado para a criança, em uma perspectiva de (co)protagonismo, implica permitir que ela ouse, experimente, seja ouvida e acolhida em suas emoções e singularidade. A literatura, o uso das diferentes linguagens, o contato com a natureza, o uso do tempo e dos espaços de maneira colaborativa contribui para a construção de um indivíduo autônomo, crítico, solidário e mais feliz. Entretanto, qual seria o lugar do docente dentro de tal perspectiva?

Para Edwards, Gandini e Forman (2018), é preciso romper a tradição didática de falar em vez de ouvir. As crianças manifestam desejos, plasticidade, vontade de comunicar e se relacionar. Porém, se não existe a disponibilidade para dar o tempo necessário, as ações ficam permanentemente truncadas. A proposta dos autores é que o adulto esteja presente sem ser intruso. É uma linha tênue e um equilíbrio delicado, porém tão necessário para que o tempo na e da escola faça sentido para a criança.

Segundo Tiriba, Barbosa e Santos (2013), para atender às expectativas dos documentos legais é necessário que se estabeleçam entre as crianças, e entre as crianças e os adultos, interações de qualidade que possibilitem uma prática social humanizadora. "O que envolve uma prática social e coletiva deve ser aquilo que nos humaniza" (TIRIBA; BARBOSA; SANTOS, 2013, p. 288). As autoras definem prática humanizadora como aquela que estabelece um cotidiano criativo, amoroso e que legitima a participação das crianças. Essa prática necessita de um professor consciente de que, da organização desses espaços e tempos, depende que se produza uma rotina de autoritarismo ou de liberdade. "Se isso não se faz sem o engajamento ético e responsável, também não se faz sem a 'paixão de conhecer o mundo"” (TIRIBA; BARBOSA; SANTOS, 2013, p. 289, grifo do original). Para as autoras, uma interação qualificada é aquela que resulta em atividade criadora, e entendem que a concepção de infância, criança e educação é o que marcará essa diferença.

Para Rinaldi (2012, p. 206), "a criança competente tem um adulto que a enxerga desse jeito" e esse olhar confere liberdade e segurança para que a criança se sinta à vontade para questionar e tecer seu próprio entendimento sobre o mundo que a cerca. Levar esta perspectiva em conta é preparar cuidadosamente os espaços e rotinas para que garantam o respeito ao ritmo, ao interesse e à inventividade das crianças. Essa postura significa romper com o instituído, ou seja, as práticas adultocêntricas em que os desejos e o olhar das crianças 
não são considerados, mas, a submissão e a aplicação de regras e conteúdos preestabelecidos pelos adultos, em uma relação verticalizada.

Considerar os interesses e desejos da criança e estimular sua criatividade requer do professor a capacidade de olhar e de escuta sensível, que nem sempre são contemplados durante a formação. Conforme destaca Rinaldi (2012), a escuta requer a humildade e a coragem de aceitar a ideia da própria incompletude. Em consonância com a perspectiva apresentada pela autora, Freire (2004) afirma que a escuta, tão importante na relação entre educador e educando, acontece quando o professor fala com seu aluno como sujeito de escuta e não como objeto do seu discurso. Para o autor, o educador que escuta na prática democrática precisa ter discutido durante sua formação sobre as qualidades necessárias a essa abordagem pedagógica e que vão paulatinamente se constituindo na prática. São virtudes como a amorosidade, o respeito às diferenças, a tolerância, a humildade, a disponibilidade para a mudança, a identificação com a esperança e com a justiça, entre outras.

A partir da escuta e de uma relação dialógica entre o professor e a criança surgem inúmeras possibilidades, experiências, aprendizagens e isso pode/deve se constituir em material de estudo. A documentação pedagógica torna-se aliada indispensável nesse movimento de ir e vir da reflexão à prática.

[...] um instrumento indispensável ao ato de estudar: o registro dos fatos e o que a eles se prende. A prática de registrar nos leva a observar, comparar, selecionar, estabelecer relações entre fatos e coisas. Educadora e educandos se obrigariam, diariamente, a anotar os momentos que mais os haviam desafiado positiva ou negativamente (FREIRE, 1997, p. 56, grifos do autor).

Fochi, Piva e Focesi (2016, p. 168) afirmam que a disponibilidade e abertura para o imprevisível, o surpreendente, fazem parte do trabalho do adulto nessa abordagem curricular, o que permite "romper com as crenças lineares, absolutas e fechadas sobre o conhecimento". Os autores compreendem a documentação como uma prática para a produção de conhecimento por meio da reflexão do professor sobre suas experiências.

Registrar, então, seria narrar uma história vivida individual e coletivamente entre crianças e docentes na busca de um significado para as experiências. "Documentação é autoria, é criação" (OSTETTO, 2017, p. 30). Nesse sentido, a formação deve buscar um modelo que considere a construção de significados a partir da história do sujeito em diálogo com a História do mundo.

Para romper com o automatismo e a repetição de práticas engessadas, a formação de professores também precisa se humanizar, incluindo as histórias e as experiências de cada professor; ela precisa ser marcada pelas muitas vozes que a compõem, abrindo espaço para o diálogo, para a formação cultural, tornando o professor responsável e responsivo, capaz de estabelecer relações dialógicas e autênticas com as crianças (PENA, 2015, p. 157).

A partir dos apontamentos anteriores, é possível pensar caminhos para que o professor, durante a formação, adquira as competências da escuta e da documentação pedagógica. Com base na experiência da instituição investigada, serão apresentadas algumas possibilidades que podem contribuir nesta perspectiva. 


\section{O registro como instrumento metodológico de formação no Pró-Saber}

Ninguém escreve se não escrever, assim como ninguém nada se não nadar (FREIRE, 1997, p. 26).

Uma formação a partir da concepção de educação democrática, adotada pela Instituição investigada, apresenta algumas particularidades no percurso das aulas e nos instrumentos metodológicos utilizados. Buscando compreender essas particularidades, e coerente com a abordagem de estudo de caso, foram utilizados diferentes instrumentos de modo a possibilitar a triangulação dos dados: (i) leitura atenta de documentos norteadores do trabalho da Instituição; (ii) entrevistas, entre março de 2016 e março de 2017, com diferentes atores: alunos da turma em andamento (5), egressos (9), professores (3), equipe gestora do Curso em questão (a fundadora, a assessora da direção e 2 coordenadores); (iii) observação de 11 aulas de julho a novembro de 2016; e, (iv) questionário online e anônimo para todos os ex-alunos.

A organização dos dados foi realizada manualmente e o tratamento dos dados foi feito sem uso de software. As categorias de análise surgiram inicialmente das perguntas formuladas a partir das hipóteses prévias à pesquisa, mas, após a entrada no campo, algumas categorias se fizeram presentes pela necessidade de compreender aspectos que não estavam previstos. O registro foi uma delas. Vale esclarecer que os nomes dos entrevistados são fictícios e não são apresentadas informações pessoais sobre nenhum dos sujeitos envolvidos na pesquisa.

A seguir, buscamos realizar a articulação entre os dados tabulados, produzidos por cada recurso metodológico, e entre esses e os aportes dos teóricos, problematizando, questionando, relativizando, em um trabalho artesanal que demandou muitas horas de reflexão cuidadosa. A partir dessas interpretações foi possível extrair as contribuições que a pesquisa pretendeu deixar.

Conforme mencionado, um dos tópicos que teve presença marcante no conteúdo do material produzido foi o registro por meio da produção de sínteses reflexivas que continham o encontro da teoria com a prática dos professores/alunos. É importante ressaltarmos que o Curso propõe uma metaformação e que os alunos são instados a viver, em uma situação de simetria invertida, um cotidiano como o esperado em sua prática profissional.

O ciclo virtuoso da metodologia adotada se resume em uma espiral de observação, reflexão, avaliação e planejamento. A cada aula o professor propõe aos alunos o que é denominado como pontos de observação. Esses pontos de observação são focos de atenção que direcionam os registros imediatos realizados ao longo da aula. Os focos de observação recaem sobre três aspectos: (i) observação sobre a própria aprendizagem; (ii) observação sobre a aprendizagem e o comportamento do grupo (dinâmica); (iii) observação sobre a coordenação da aula pelo professor. Todos os alunos têm a tarefa de observar a própria aprendizagem, mas a cada aula é solicitado que um aluno registre a dinâmica, ou seja, como o grupo se conduziu frente aos conteúdos e atividades propostas, e a outro aluno é solicitado que registre os aspectos relacionados à condução da aula pelo professor. Esses registros são 
lidos ao final da aula e se constituem na avaliação que ajudará o professor a adequar seu planejamento para as aulas seguintes.

Segundo alguns dos entrevistados, uma das aprendizagens mais importantes construídas durante o curso foi a forma de olhar, sobretudo para os seus próprios alunos, e o exercício constante da observação foi fundamental para essa aprendizagem. Ostetto (2012, p. 22) afirma que a observação de uma situação pedagógica requer um olhar "aberto, sensível e acolhedor", e destaca que o exercício da escrita pode contribuir para a modificação da forma de olhar as crianças. A autora lembra que o nosso olhar, em geral, está mais focado na falta e na busca de um padrão de comportamento marcado pelo controle do corpo. Na concepção democrática de educação, as crianças também são protagonistas e o cotidiano é marcado pelo mesmo processo de autoria. Nessa perspectiva, as crianças também são levadas a registrar suas produções e o professor se converte em escriba dos pequenos, propiciando às crianças as mesmas possibilidades que os registros trazem para a própria formação (OSTETTO, 2012).

A fala de Rafaelai, aluna da turma em curso, apresentada a seguir, ressalta sua surpresa com as possibilidades no trabalho com os bebês, e que o exercício de observação e de abertura sensível durante o curso ajudou-a a perceber o potencial latente das crianças da sua turma do berçário.

\footnotetext{
Uma coisa que sempre me encucou muito era como fazer isso com o berçário. A gente percebe que é possível, tem possibilidades, tem brechas e eles vão dando as pistas e aí sim, você precisa ter esse olhar muito apurado, que a gente vai desenvolvendo através da nutrição estética, através das observações. Observação com foco, observação mais aberta, isso tudo vai fazendo com que você fique mais sensível e mais atenta aos movimentos e interesses da criança (Rafaela - aluna da turma em curso).
}

Guimarães e Kramer (2009) apontam o olhar como referência nas interações com os bebês. "O mergulho nas possibilidades das coisas e no chamamento do mundo é conduzido e possibilitado pelo olhar, que muitas vezes vai do objeto para o adulto e deste para o objeto, quando a criança está indo em direção ao novo" (GUIMARÃES; KRAMER, 2009, p. 105).

De fato, para estar com crianças que ainda não se comunicam com palavras, é necessário um adulto que esteja atento às outras formas de expressão que a criança lança mão em uma relação marcada pela disponibilidade. Esse olhar marcado pela atenção e solidariedade é característico de uma relação humanizada e se traduz em uma "ética do interesse" (TRISTÃO, 2004, p. 7). Segundo a autora, o registro é importante para que um cotidiano marcado pela intencionalidade do docente seja planejado a partir das manifestações das crianças.

Em uma das aulas observadas ao longo da pesquisa aqui apresentada, a professora Madalena Freire ${ }^{\mathrm{ii}}$, que também é a coordenadora pedagógica do curso, ressalta que o tema abordado seria o registro como instrumento metodológico de formação. Neste momento, foi possível apreender que, de acordo com a proposta pedagógica adotada pelo Pró-Saber, são praticados três tipos de registros: (i) o registro no ato ou corrido, quando, a partir da observação, são feitas pequenas anotações sobre o que está acontecendo "no calor da aula". Sua função é reter os fatos para não esquecer e servir de apoio para as notas imediatas; (ii) as notas imediatas são pequenos textos escritos logo após a aula e servem para registrar um 
pouco mais detalhadamente, ainda no clima; (iii) o registro reflexivo, que requer um distanciamento, é feito com base nos registros anteriores e implica em um posicionamento sobre o ocorrido. Os registros recebem o status de mola central que agiliza o pensamento reflexivo.

\begin{abstract}
Por que tanta ênfase no registro? Ele é tomada de consciência de sua autoridade e responsabilidade, de pessoa pública, na frente de uma criança da qual você nunca mais vai sair da vida dela. O registro é arma de luta, para apropriação da sua autoria e autonomia, que é ser dono da sua liberdade (Madalena Freire - registro realizado durante a observação da aula de 29/9/2016).
\end{abstract}

Para que a síntese reflexiva cumpra papel tão fundamental, o texto é escrito em forma de narrativa. A narrativa é uma comunicação artesanal, portanto única. $\mathrm{O}$ artesanato, contrariamente à produção em série, demanda tempo e dedicação pessoal. É produto de uma experiência pessoal. A linguagem tem uma potência salvadora para o empobrecimento da experiência na modernidade (SOUZA; KRAMER, 2009). Sendo assim, nomear o que fazemos em educação pode se converter em práxis reflexiva.

O registro narrativo possibilita ao professor incluir-se no texto com sua subjetividade, seus impasses e conflitos, porém de uma maneira propositiva, levando seus registros para o campo das possibilidades, uma vez que tem o objetivo de repensar suas práticas. As narrativas articulam o cotidiano ao trabalho reflexivo.

De certa forma, as lições registradas deixam de ser um evento particular para tornarse experiência compartilhada: autor, personagens e interlocutores encontram no texto um ponto para diálogo e elaboração de reflexões acerca das próprias vivências. Assim, narrar não é um compromisso individual, mas um compromisso eticamente orientado com o mundo (FERREIRA; PRADO; ARAGÃO, 2015, p. 213).

Para as autoras, as reflexões pessoais são produzidas socialmente, carregam, portanto, o coletivo, e voltam a ele em um gesto de partilha. Nesse sentido, escreve-se com um propósito, uma intenção, uma utilidade, que, segundo Benjamin (2012), é o de fazer diferença na vida daquele que lê seu registro.

Os depoimentos apresentados a partir das entrevistas demonstraram que o exercício do registro reflexivo é uma forma de se apropriar dos conhecimentos e de compartilhar com seus pares. Essas sínteses parecem se caracterizar por uma retomada da experiência vivida com o distanciamento necessário para compreender as situações de outra maneira e perceber outras formas de agir. Revisitar certezas sedimentadas e quebrar o velho para acolher o novo. Em pesquisa anteriormente citada, foi apontado que o registro de experiências vividas e narradas "pode alterar a percepção dos professores sobre seu cotidiano de trabalho e permitir a produção, apropriação e circulação de novos saberes educacionais" (FERREIRA; PRADO; ARAG ̃̃O, 2015, p. 210).

O desafio da escrita reflexiva de maneira intensa e intensiva foi mencionado diversas vezes pelos egressos entrevistados em função da quantidade de sínteses requisitadas, mas, ao mesmo tempo, porque a escrita organiza ideias que muitas vezes estão soltas, sem que o sujeito se dê conta, como verificado na fala a seguir: 
Fazer um registro a cada dia para nós foi algo surpreendente. Eu sou fruto de uma educação tradicional. Eu senti muita dificuldade na escrita, muita dificuldade na escrita! Até na construção do pensamento. Eu penso muito antes de falar e na hora da escrita era a mesma coisa. Para mim, as disciplinas que eu tive que escrever mais foram muito difíceis e esse exercício da escrita para mim foi fundamental, até mesmo para passar no concurso (Daniel - egresso do curso).

Ao indagarmos se as sínteses eram corrigidas por alguém, o entrevistado explica que a leitura era feita pelo professor da disciplina correspondente.

Ele avaliava se era pertinente ao assunto e ele fazia uma devolução. Era sempre assim: você escreve, o professor avalia. Ele lê e te devolve; ele escreve um texto também, então, tanto o professor como o aluno escrevem bastante. E o aluno sempre tem que fundamentar porque ele escreveu aquilo, então escrever é difícil (Daniel - egresso do curso).

A fala de Daniel encontra eco no questionamento de Ostetto (2012) sobre a dificuldade apresentada pelos professores nesse exercício da escrita. Será que essa dificuldade é decorrente da falta de incentivo em nossa vida escolar para utilizar a escrita como espaço de autoria e reflexão? A autora ratifica que a escrita é um exercício que demanda esforço, disciplina e coragem para estar frente a frente com as próprias dificuldades e conflitos internos. Nas conversas informais com a turma em curso, no momento de realização da pesquisa, estes aspectos também foram apontados como principais dificultadores, como é possível constatarmos nos trechos a seguir.

No primeiro ano eu sofri muito. Eu não sei se eu não tivesse passado no concurso se eu continuaria. Primeiro porque você aceitar mudar é muito difícil, muito, muito difícil (Rafaela - aluna da turma em curso).

A gente tem um volume de trabalho muito alto. Para quem trabalha o dia inteiro, ter trabalho todo dia... É claro que eu entendo, hoje principalmente, o quanto isso me acrescentou, mas é muito difícil dar conta disso tudo e não querer fazer um negócio assim de qualquer jeito. Acho que isso é uma das coisas que mais me estressam (Luciana - aluna da turma em curso).

Entretanto, assim como os egressos entrevistados, os alunos da turma em curso reconheceram que, apesar de cansativo, o exercício da escrita tinha sido fundamental e esse reconhecimento já se dava antes do término da formação. Alguns haviam prestado concurso e ficaram impressionados com a fluidez do próprio texto. As sínteses são guardadas como material de estudo, pois incluem nos textos a articulação com a própria prática, as possibilidades de levar a teoria estudada para o cotidiano e os aportes do professor da disciplina. O trecho abaixo, enviado por meio do questionário, demonstra a força que o hábito adquire depois de enfrentadas as dificuldades iniciais.

Lembro-me da primeira aula com Madalena em que todas as 36 alunas esperavam a matéria no quadro. Quando Mada nos disse: "vamos minha gente, anotem o que vocês conseguem absorver enquanto conversamos", ficamos perplexas com a metodologia. Hoje é como se fosse parte de meu sangue registar. Me sinto incomodada quando não registro mesmo que notas imediatas (Anônimo). 
A escola é de fato espaço privilegiado para o exercício da escrita autoral e de práticas colaborativas tão necessárias para a construção de autonomia e liberdade cidadã, como afirmam Souza e Kramer (2009, p. 239):

\begin{abstract}
A escola nunca foi tão fundamental nesta recomposição dos fragmentos. Sua função hoje não deveria se pautar na transmissão do conhecimento, mas sim na possibilidade de socialização de discussão e digestão das informações, no resgate da historicidade, na troca, na interlocução, na composição [...] é um dos poucos espaços que tem as condições de restaurar a convivência, a fala, a escuta e a expressão e também de possibilitar a crítica e a reflexão, resgatando a humanidade do homem.
\end{abstract}

Mas como a escola pode se converter em espaço de resgate da humanidade se os educadores não tiverem passado por uma formação que leve em conta essa perspectiva? A fala dos entrevistados demonstra que a percepção dos alunos associa uma formação humana com o fato de serem reconhecidas em sua singularidade, de serem olhados, ouvidos, abraçados, de sentirem-se respeitados. Em consonância com as ideias defendidas por Vigotski (2007), a história prévia dos alunos é reconhecida e considerada, pois são feitos de substância cultural em uma mistura única e pessoal.

Para aprender a olhar o outro para além do aparente é necessário ser capaz de ver a si mesmo. Nesta perspectiva, Ostetto (2012, p. 130) defende que durante a formação o professor se encontre com a criança que foi, pois considera que acessar "conteúdos inconscientes é essencial no processo de tornar-se professor, principalmente porque seu ofício se dará em relações". Acontece que esse reencontro consigo mesmo faz emergir sentimentos e emoções que raramente encontram um espaço no mundo acadêmico e profissional. Será que a universidade, como lugar onde se pensa e se faz educação, tem garantido espaços para o resgate dessa humanidade, permitindo que seus sujeitos escapem de uma vivência que apenas contribuirá para a manutenção daquilo contra o qual nossos discursos denunciam?

O mergulho na própria subjetividade foi descrito como indispensável para a ressignificação das experiências vividas, pelos alunos ao longo do curso, proporcionando o conhecimento de si mesmo e o empoderamento pessoal e profissional. Essa arqueologia da memória também contribui para o exercício da empatia e da tolerância com as diferenças e só pode acontecer em um ambiente em que o sujeito se sinta livre e acolhido. "É essa memória que alicerça a consciência histórica, política e pedagógica desse sujeito" (FREIRE, 2008, p. 41).

A investigação foi evidenciando que o registro reflexivo sobre a prática do professor, e a documentação pedagógica em um exercício coletivo com as crianças, adquirem uma dimensão maior do que o registro descritivo das ações docentes empreendidas.

O aprendizado do registro é o mais poderoso instrumento na construção da consciência pedagógica e política do educador, pois, quando registramos, tentamos guardar, prender fragmentos do tempo significativamente vivido, para mantê-los vivos como registro de parte de nossa história, de nossa memória (GENESCÁ; CID, 2013, p. 75).

Os dados produzidos, a partir das entrevistas, demonstram que o fato de terem sido estimulados a encontrar a própria voz ao longo do curso, contribuiu para que os egressos se 
sentissem mais confiantes e valorizados enquanto sujeitos. A sensação de empoderamento também foi reconhecida de diferentes maneiras, como é possível observarmos em algumas das respostas enviadas por meio do questionário.

O Pró-Saber me deu as ferramentas que eu precisava para crescer profissionalmente, fez com que a minha prática fosse mais consciente, que a minha postura fosse mais consciente de que o meu ensinar e o meu aprender vem das trocas com as crianças, com os adultos, com o mundo ao meu redor (Anônimo).

Ele [o curso] me proporcionou conhecimento, segurança e sabedoria para atuar junto aos pequenos respeitando a individualidade de cada um (Anônimo).

Posso dizer que esse curso apostou em mim, mostrando que sou autora na minha busca contínua de novos conhecimentos (Anônimo).

O compromisso e a responsabilidade que assumem com as crianças também foi um aspecto bastante mencionado

Você não pode tratar as crianças como se fossem todos iguais. Principalmente, você tem que olhar para aquela criança como um ser único, não é igual a ninguém, ele tem a sua história, tem a sua vida, e isso você tem que respeitar. A partir daí, desse vínculo que você vai criar, a partir do conhecer, do respeitar, você vai dar um trabalho diferenciado para ele dentro da sala de aula (Lara - egressa do curso).

[...] quando a criança chega à creche ela traz uma bagagem dentro de si e nós temos que levar em consideração essa bagagem que a criança traz, suas vivências, sua cultura. Então a gente vê, observa muito, ouve eles para depois trabalhar em cima (Jade - aluna da turma em curso).

As falas indicam que a criança é vista como única em sua singularidade e que precisa ser considerada como sujeito ativo de seu desenvolvimento. É importante "[...] mais do que 'dar voz' à criança, escutá-la e responder a ela de forma responsável” (BARBOSA; MAIA; RONCARATI, 2013, p. 228, grifo do original). As narrativas dos professores apontam para uma maior consciência da importância do próprio trabalho e, consequentemente, da responsabilidade que carregam. Alguns reafirmaram o compromisso com as marcas que sabem que vão deixar na vida de cidadãos de pouca idade. Outros manifestaram o desejo de realizar conquistas políticas e sociais por meio da educação e se consideram agentes transformadores da sociedade. Estes desejos vão ao encontro da perspectiva histórico-social de Freire (2004). Para o educador, a prática educativa humanizante deve estar impregnada do sentido da utopia, em que a história é vista como possibilidade e não de forma determinista.

\section{Considerações finais}

A investigação demonstrou que, apesar de trabalhoso, o registro regular e reflexivo, ou seja, aquele sobre o qual o escritor volta a se debruçar e analisar, traz um potencial emancipador, pois permite a tomada de consciência dos pensamentos, sentimentos e valores que norteiam seu trabalho. O registro na forma de narrativa constitui-se em processo de autoria que marca posicionamentos diante da realidade e caminhos escolhidos pelo professor em seu trabalho. Conforme destacam Ferreira, Prado e Aragão (2015), a postura reflexiva 
frente ao seu cotidiano não é um gesto natural do educador, é uma prática social que precisa ser desenvolvida.

O exercício contínuo e reflexivo da escrita sobre a própria prática também demonstrou contribuir para a constituição da profissionalidade do professor pesquisador, uma vez que, nesse processo de análise, o professor produz sua própria teoria. Essa teoria se constituiria no amálgama entre o que se aprende teoricamente na formação e a confrontação com a realidade em que está inserido, em uma dinâmica dialógica com a subjetividade do sujeito. A escrita, nessa perspectiva, permite, então, a objetivação dos saberes profissionais necessária à conquista do seu espaço no campo da produção de conhecimento.

\footnotetext{
Essa validação do trabalho prático do professor é o único "livro texto" rico com o qual podemos contar no desenvolvimento de nossas reflexões sobre a educação. Além disso, o trabalho de professores, quando não abandonado a si mesmo, quando não deixado sem o apoio de instituições e das alianças com colegas e famílias, é capaz não apenas de produzir experiências educacionais diárias, mas também é capaz de se transformar no sujeito e objeto de reflexão crítica (EDWARDS; GANDINI; FORMAN, 2018, p. 91, grifo do original).
}

Foi possível perceber que o professor de profissão possui um conhecimento que paradoxalmente desconhece ou, muitas vezes, desvaloriza. Em várias entrevistas, os egressos declararam que, dentre os benefícios de ter passado pelo curso, um deles era ter podido dar nome ao que já sabiam e faziam. Essa percepção contribuiu para o empoderamento e a elevação da autoestima mencionados e indica que o encontro da teoria com a prática ajuda o professor a construir um repertório pessoal de alternativas para enfrentar a realidade do cotidiano, fortalecendo a confiança no próprio trabalho. Esse repertório de saberes experienciais pode conferir voz e representatividade ao profissional da educação que tem sido relegado a um papel passivo de executor das teorias que se criam longe do chão da escola.

Para Fochi, Piva e Focesi (2016), o propósito da documentação pedagógica é a comunicação, por meio de narrativas, das experiências e percursos vividos pelos professores e o desenvolvimento das crianças. Trata-se de produção de conhecimento dentro da escola, "do professor que diante de sua práxis, reflete para tornar visível suas crenças, valores e horizontes teóricos que são engendrados no cotidiano da escola" (FOCHI; PIVA; FOCESI, 2016, p. 175).

A relação de exterioridade que existe entre os professores e os saberes curriculares de sua formação profissional gerou uma divisão social do trabalho intelectual entre os que produzem os saberes e os que os reproduzem. A educação infantil, cujas práticas e formas de organização com frequência são análogas às do ensino fundamental, não escapou dessa lógica de produtividade e exterioridade em que os saberes experienciais dos professores não são percebidos como legítimos. Somado a essa situação, a pressão pela alfabetização acaba levando os professores a buscar, muitas vezes, um reconhecimento de sua competência por meio da antecipação das práticas escolarizadas do ensino fundamental I (MICARELLO, 2006).

Assumir o papel de coautor das teorias que alimentam a prática como estratégia de profissionalização do corpo docente, exigirá uma efetiva parceria entre professores, corpos universitários de formadores e responsáveis pelo sistema educacional. Os estudos na área 
defendem que o desafio para a formação dos professores passa por um maior espaço para conhecimentos práticos nos currículos dos cursos de graduação. Para que os saberes experienciais sejam legitimados e reconhecidos é preciso que passem por um processo de objetivação.

De acordo com a investigação aqui apresentada, o registro tem se mostrado um recurso precioso neste processo de objetivação que parte da tomada de consciência dos próprios saberes. Nesse sentido, fica o convite para que os leitores/professores se apropriem da escrita reflexiva, que traz consigo a possibilidade de constituir o sujeito em sujeito do conhecimento e autor do próprio discurso.

\section{Referências}

BARBOSA, Silvia Neli Falcao; MAIA, Marta Nidia Maia; RONCARATI, Mariana. 'Ela aproveita para andar aqui': as crianças e as instituições de educação infantil. In: KRAMER, Sonia; NUNES, Maria Fernanda; CARVALHO, Maria Cristina (org.). Educação Infantil: formação e responsabilidade. Campinas: Papirus, 2013. p. 227-242.

BENJAMIN, Walter. Magia e técnica, arte e política. Ensaios sobre literatura e história da cultura. 8 ed. São Paulo: Brasiliense, 2012.

BRASIL. Ministério da Educação. Secretaria de Educação Básica. Diretrizes Curriculares Nacionais para a Educação Infantil. Brasília: MEC, SEB, 2010. Disponível em: https://ndi.ufsc.br/files/2012/02/Diretrizes-Curriculares-para-a-E-I.pdf. Acesso em: 17 jul. 2018.

EDWARDS, Carolyn; GANDINI, Lella; FORMAN, George. As cem linguagens da criança. A abordagem de Reggio Emilia na educação da primeira infância. Tradução de Dayse Batista. Porto Alegre: Penso, 2018.

FERREIRA, Luciana Haddad; PRADO, Guilherme do Val Toledo; ARAGÃO, Ana Maria Falcão de. A formação do professor por suas narrativas: desafios da docência. Revista Hipótese. Itapetininga, v. 1, n. 4, p. 204-227, 2015.

FOCHI, Paulo Sergio; PIVA, Luciane Frosi; FOCESI, Luciane Varisco. A documentação pedagógica como mote para a formação de professores: o caso de uma escola participante do OBECI. Crítica Educativa. Sorocaba/SP, v. 2, n. 2, p. 165-177, jul./dez. 2016.

FREIRE, Madalena. Educador. São Paulo: Paz e Terra, 2008.

FREIRE, Paulo. Professora sim, tia não: cartas a quem ousa ensinar. São Paulo: Olho D’água, 1997.

FREIRE, Paulo. Pedagogia da Autonomia. 29 ed. São Paulo: Paz e Terra, 2004.

GENESCÁ, Ana Carpenter; CID, Lucia de Araujo (org.). Pró-Saber: imaginação e conhecimento. Edições Pró-Saber, 2013. 
GUIMARÃES, Daniela Oliveira de; KRAMER, Sonia. Nos espaços e objetos das creches, concepções de educação e práticas com crianças de 0 a 3 anos. In: KRAMER, Sonia (org.) Retratos de um desafio: crianças e adultos na educação infantil. São Paulo: Ática, 2009. p. 82-94.

MICARELLO, Hilda. Professores da pré-escola: trabalho, saberes e processos de construção de identidade. 2006. 212 f. Tese (Doutorado em Educação) - Departamento de Educação, Pontifícia Universidade Católica do Rio de Janeiro, Rio de Janeiro, RJ, 2006.

MICARELLO, Hilda. Formação de professores da educação infantil: puxando os fios da história. In: ROCHA, Eloísa Acires Candal; KRAMER, Sonia. Educação infantil: enfoques em diálogo. 3 ed. Campinas: Papirus, 2013. p. 211-227.

NUNES, Maria Fernanda; CORSINO, Patricia; KRAMER, Sonia. Educação infantil e formação de profissionais no Estado do Rio de Janeiro (1999-2009). Relatório de pesquisa. Rio de Janeiro: Traço e Cultura, 2011.

OSTETTO, Luciana Esmeralda (org.). Educação infantil: saberes e fazeres da formação de professores. 5 ed. Campinas: Papirus, 2012.

OSTETTO, Luciana Esmeralda (org.). Registros na educação infantil: pesquisa e prática pedagógica. 1 ed. Campinas: Papirus, 2017.

PENA, Alexandra Coelho. "Para explicar o presente tem que estudar a história do passado": narrativas de profissionais de escolas comunitárias de Educação Infantil da Baixada Fluminense. 2015. 165 f. Tese (Doutorado em Educação) - Departamento de Educação, Pontifícia Universidade Católica do Rio de Janeiro, Rio de Janeiro, RJ, 2015.

RINALDI, Carla. Criatividade como qualidade do pensamento. In: RINALDI, Carla (org.). Diálogos com Reggio Emilia: escutar, investigar e aprender. São Paulo: Paz e Terra, 2012. p. 203-217.

SOUZA, Solange Jobim; KRAMER, Sonia (org.). Política; Cidade; Educação: itinerários de Walter Benjamin. Rio de Janeiro: PUC-Rio, 2009.

TIRIBA, Lea, BARBOSA, Silvia Néli, SANTOS, Núbia. O cotidiano da Educação Infantil: Buscando interações de qualidade. In: KRAMER, Sonia; NUNES, Maria Fernanda; CARVALHO, Maria Cristina (org.). Educação Infantil: formação e responsabilidade. Campinas SP: Papirus, 2013. p. 279-294.

TRISTÃO, Fernanda. Ser professora de bebês: uma profissão marcada pela sutileza. Zero-aseis. Florianópolis, v. 6, n. 9, p. 1-14, jan. 2004.

VIGOTSKI, Lev Semenovich. A formação social da mente: o desenvolvimento dos processos psicológicos superiores. 7 ed. São Paulo: Martins Fontes, 2007.

\section{Notas}

${ }^{\mathrm{i}}$ Os nomes dos entrevistados são fictícios. 

ii Madalena Freire é arte-educadora e pedagoga. Dedica-se desde 1981 à formação de professores, especialmente
de educação infantil. É coordenadora pedagógica do Curso Normal Superior do Instituto Superior de Educação
Pró-Saber. 